\title{
Towards a Generic e-Market Design
}

\author{
Dirk Neumann, \\ Carsten Holtmann, \\ Henning Weltzien, \\ Christoph Lattemann, and \\ Christof Weinhardt \\ Universitaet Karlsruhe (TH) \\ Department of Economics and Business Engineering \\ Chair for Information Management and Systems \\ Karlsruhe, Germany \\ \{neumann|holtmann|weltzien|lattemann|weinhardt\}@iw.uni-karlsruhe.de
}

\begin{abstract}
The design of the microstructure of electronic markets is crucial for their success. Less effort has been made in this area, especially for commodity markets. This paper illustrates five key problems of e-market design and introduces the concept of cascading dynamic market models as a promising solution to cope with most of them. Taking the multi-dimensional character of commodities into consideration, further research in this area is encouraged. Furthermore, the project 'Electronic-Financial-Brokerage as knowledge intensive services - a generic approach' dealing with those problems is briefly presented
\end{abstract}

Keywords: E-Market Design, Parametric Design, Market microstructure, Market Server, (Cascading) Dynamic Market Models

\section{RISE AND DECLINE OF B2B-MARKETS}

The last years have witnessed the emergence of several electronic marketplaces in almost any sector of the economy. The last two years have also experienced the silent disappearance of most of these marketplaces. Rise and decline of B2B-markets reveal that electronic markets certainly add value to traders, but obviously the advent of those markets concurred with some major disadvantages.

\footnotetext{
The original version of this chapter was revised: The copyright line was incorrect. This has been corrected. The Erratum to this chapter is available at DOI: 10.1007/978-0-387-35617-4_48 
As a reason for the success story stands the undisputed ability of emarkets to speed up processes, provide access for global buyers and sellers, reduce search costs, increase efficiency, and overall reduce transaction costs (Malone, Yates et al. 1987). Empirical data reveals that in 1999 more than 1,000 markets existed, which generated a turnover of approximately $\$ 8.7$ billion (Forrester Research 1999). The estimates of professional research groups projected a steady growth of the total number of market facilities as well as turnover. For example Gartner Group suggested more than 1,400 marketplaces operating in the year 2001, and a turnover of $\$ 7,290$ billion in the year 2004 (Knight 2000).

At the beginning of the year 2002 we know that those estimates have not come true in the projected timeframe. The burst of the Internet bubble also seized the B2B-markets. More and more established competitors dropped out of the market (for example Efdex Limited). Main argument for the decline of e-market was the insight that there were too many e-markets active. Almost every industry supported several e-markets. This fragmentation means a split up of the liquidity. Due to the existence of many e-markets the order flow on a single e-market never surpassed the critical mass. As a consequence, practitioners and researchers agreed that a consolidation process among the e-market would cure the shaken marketplace industry. Hitherto, the recovery process has not yet started.

Clearly, missing liquidity condemns a marketplace to exit the market. The liquidity problem is definitely a chicken and egg problem. One way to promote a network good (the marketplace) is to influence the expectation of the number of participants at the market (Shapiro, Varian 1999). In the case of e-marketplaces this can particularly be achieved by the market structure. Recent studies have shown that the participants were dissatisfied with the market services (Capers, Bartels et al. 2001). As such e-market design obtains an important function for online marketplaces.

The remainder of the paper is structured as follows: In section two the facets of e-market design are introduced. Depicting the issues already discloses the inherent problems of e-market design. Some of these problems have been studied for decades, whereas others have been neglected. We pick up the aspects that are rarely examined and present a generic approach to customer-oriented e-market design. Section three closes with a short summary and provides a brief description of the project 'ElectronicFinancial-Brokerage as knowledge intensive services - a generic approach' motivating future research in the field of multi-attribute e-market design. 


\section{GUIDING PRINCIPLES FOR E-MARKET DESIGN}

In literature, design process in general is often pinpointed as a process that maps needs to function to structure (Brown 1993). The needs of the users are explicitly formulized and translated to a specific structure that meets those needs. Following this insight $e$-market design can be perceived as a customer-orientated process of constructing an adequate market model (often referred as market structure).

Rakishly formulated, the market model describes the underlying trading rules of the e-market. Abstracting from actual implementations any market model comprises several phases that are sequentially executed. The basic intuition behind this abstraction is the observation that any offer (e.g. bid/ask order) passes through the phases (or parameters as we will refer to them in the following): (1) offer specification, (2) winner determination with "embedded price discovery", (3) and an allocation with a winner's notification before an exchange transaction occurs.

What determines the market model is simply the definition of the "How". For instance the price discovery mechanism "English auction" defines how the price is found. Accordingly, the market model is described by its values of the parameters. E-market design constitutes an assignment problem, since the designer decides what value set is assigned to the parameter set in order to meet the customers preferences expressed by a set of preferences.

Formally e-market design is the mapping from a four-dimensional problem space $<\mathrm{P}, \mathrm{V}_{\mathrm{i}}, \mathrm{C}, \operatorname{Pr}>^{1}$ to a set of solution market models $\left\{\mathrm{M}_{1}, \mathrm{M}_{2}, \ldots, \mathrm{M}_{\mathrm{n}}\right\}$ (Motta, Zdrahal 1996).

It comprises the following elements:

$\mathrm{P}=$ Parameters $=\left\{\mathrm{p}_{1}, \ldots, \mathrm{p}_{\mathrm{n}}\right\} ;$

$\mathrm{V}_{\mathrm{i}}=$ Values $=\left\{\mathrm{v}_{\mathrm{il}}, \ldots, \mathrm{v}_{\mathrm{il}}\right\}$

$\mathrm{C}=$ Constraints $=\left\{\mathrm{c}_{1}, \ldots, \mathrm{c}_{\mathrm{n}}\right\}$;

$\operatorname{Pr}=$ Preferences $=\left\{\mathrm{pr}_{1}, \ldots, \mathrm{pr}_{\mathrm{n}}\right\}$;

As previously mentioned, a market model is uniquely defined by the assignment of values to the parameters. That is, market model $\mathrm{M}_{\mathrm{k}}=\left\{\left\langle\mathrm{p}_{\mathrm{i}}, \mathrm{v}_{\mathrm{ij}}\right\rangle\right\}$ where $\mathrm{p}_{\mathrm{i}} \varepsilon \mathrm{P}$, and $\mathrm{v}_{\mathrm{ij}} \varepsilon \mathrm{V}_{\mathrm{i}}$.

E-market design is, however, an intricate process, due to the following problems:

\section{NOTES}

${ }^{1}$ Parametric Design literature usually adds requirements and a cost function to the problem space. For simplicity we omit requirements by assuming that the constraint set encompasses the weaker form of requirements. Furthermore we abstract from a cost function, since we will not use it in the remainder of the paper. 
a) Size of the Design Space

The collection of all conceivable market models that can be generated form the design space. Clearly, the size of the design space is determined by the choice of the feasible values. One can envision that the design space is simply huge (Bulow, Roberts 1989). For instance, if we take five parameters to describe the structure with six values each, we obtain $6^{5}=60.466 .176$ different market models. Selecting one out of 60.466 .176 that satisfies all the constraints $\mathrm{C}$ and thereby maximizes preferences $\mathrm{Pr}$ is quite difficult.

b) Uncertainty about the impact of the single values on the market performance

In many different fields the impact of the market structure on the market performance has been studied for a long time. For example in Finance ${ }^{2}$ market microstructure theory aims at analyzing the effect of different parameter values $\left\langle\mathrm{p}_{\mathrm{i}}, \mathrm{v}_{\mathrm{ij}}\right\rangle$ on market success. Formal models taking the degree of order transparency, order anonymity, trading frequency, price discovery mechanism and many more (for a nice overview see O'Hara 1997) into consideration. Nonetheless, due to the models' inherent sensitivity to the underlying assumptions, an overall consistent picture of the pure effects of the values does not exist.

c) Uncertainty about the impact of market models on the market performance

If the impact of the elements forming a market model is roughly known, it is not astonishing that the effect of a composite $\left\{\left\langle\mathrm{p}_{\mathrm{i}}, \mathrm{v}_{\mathrm{ij}}\right\rangle\right\}$, the market model, is also vague. Adding the values together to a market model (or at least to a building block ${ }^{3}$, i.e. an auction type) adds positive as well as negative effects to an aggregate. In what direction this aggregate will lead is ambiguous as the effects of the single values are uncertain.

Traditional game theory and market microstructure theory cannot cope with the complexity inherent to real world problems (Roth 2000). As a consequence, a growing field of experimental economics has emerged. In laboratory surveys the link between market model (or market institutions) and market performance is subject to research.

\section{d) Heterogeneous preferences among investor groups}

Hitherto, we assumed that a preference set can be defined. However, Arrow's paradox revealed that the aggregation of individual preferences can be intransitive (Arrow 1963). In these cases a reasonable preference set cannot be formulated. As a consequence, a single market model does not meet all of the market participants' needs. This argument reflects the

${ }^{2}$ In this context market microstructure theory is a worthwhile field of study since it primarily studies (financial) exchanges. Most of its insights can be easily applied to non-financial products. Nonetheless determining whether or not a specific effect can be transferred to another B2B-market must be carefully examined.

${ }^{3}$ In the remainder of the paper we define building blocks as a fixed set of parameter values. 
findings of the market microstructure theory that market models „...typically favours one investor group at the expense of another group" (O'Hara 1997).

e) Inconsistent preferences over time

The task of e-market design is even more exacerbated by the fact that the preferences of the participants may change over time. If a trader prefers market model $\mathrm{M}_{\mathrm{A}}$ (say a market model with anonymity) because of his trading motive in time $\mathrm{t}$ (information-oriented trading due to superior information) represented by $\mathrm{Pr}$, it is possible that he will prefer market model $\mathrm{M}_{\mathrm{B}}$ in time $\mathrm{t}+1$ (say a market model without anonymous bidding) because his trading motive has changed to Pr' (liquidity-oriented trading). Putting it to an extreme, it is possible that the preferences alter from transaction to transaction.

Researchers in many fields are already aware of the missing link, how the market model affects the market performance (problems b \& c). Even the design space problem (problem a) is tackled, the exploration just begun. Especially in the field of auction theory, various auction types are constructed and evaluated (Wurman 1999). Less attention has been spent to the unstable and inconsistent nature of the preferences (problems $d \&$ e). In fact, e-market design in practice is actually tailored to specific (median) investor groups deemed to be most profitable instead of meeting all the investors' needs.

In order to remedy this shortcoming in research and practice we present three hypotheses that appears to be worthwhile to study. First, a generic market model approach is motivated to deal with inconsistent preferences among different user groups. Second, the use of dynamic market models is suggested in order to alleviate the problem of time-inconsistent preferences. By doing so dynamic market models are linked to the undesired effect of fragmenting the market. Third, the concept of cascading dynamic market models is discussed intending to integrate several market models.

\subsection{Hypothesis 1: Multiple (Generic) Market Models matter}

An operator of a (B2B) e-market is frequently faced with the problem, which market model to choose. If he selects one based upon a profound analysis of the potential participants needs and implements this market model, a modification of this decision is expensive and time-consuming taking the implementation work into account. Thus, the operator is locked-in the market model he established. Since the preferences of the market participants can and presumably will change (recall problem e), this approach is very perilous.

One way to avoid being trapped by a lock-in, the operator can make use of a generic market system. Such a generic market system, or market server, 
can run multiple market models by supporting the parametric configuration of the values. The research prototype Michigan AuctionBot developed at the University of Michigan (Wurman, Wellman et al. 1998) epitomizes the idea of a market server. It can be used to develop online marketplaces that implement a wide variety of markets (auctions). This is achieved by decomposing the (auction) design space into a set of orthogonal, i.e. independent parameters $\mathrm{P}$ (e.g. bidding rules, information revelation rules, and clearing rules). By simply adding up the parameter values new auction types are defined.

There are two major advantages of a market server to traditional emarkets providing only a single market model.

First, the dynamics of the market and trade usances create uncertainty concerning the market model that matches the objectives of the market participants. In this context, a market server grants the necessary flexibility to adapt the changing requirements (Wrigley 1997).

Second, a market server implements the idea of versioning. Put it simple, by providing heterogeneous customers ${ }^{4}$ with different versions of a product, the overall revenue of the seller can be (significantly) increased (Varian 2000). Transferred to e-market design, an additional market model can be seen as another version and thus can contribute to the revenue base: multiple market models"[...] allow existing participants to connect and interact in even more ways, providing the flexibility that real worlds markets demand and spawning more transactions within the marketplace. Because each mechanism attacks a different business inefficiency, the market that provides the full range of trading mechanisms will most optimally serve its buying and selling communities, as well as create complementary revenue streams for itself" (Idapta 2000). Frequently, the operator cannot identify the trader's membership to a certain group, so the traders themselves have to self-select their appropriate market model. Nonetheless, the difficulty is now to arrange the packages (market models) in a reasonable manner, such that they meet the investor groups' needs.

Obviously, a generic approach accounts for inconsistent and heterogeneous preferences, but there are also some disadvantages. Notwithstanding, it cannot fully solve the design space problem: What parameter values should be included? One way for the designer as a decision maker to avoid being trapped in a morass of possibilities is to bound the number of values. However, restricting the design space can lead to the exclusion of the appropriate market models. The impending trade-off between complexity and desirable outcomes tremendously complicates the design process. Technical feasibility in the provision of a market server may naturally limit the design space and thus automatically reduce complexity.

4 In the versioning model, heterogeneous customers are characterized by a different willingness-to-pay. 
The previously mentioned uncertainty problems (recall problem $\mathrm{b} \& \mathrm{c}$ ) remain unsolved. Even the provision of multiple market models requires deep knowledge about the direct impact on the market performance. The immanent danger of employing the wrong market models is in the light of the huge design space still viable.

Two more drawbacks apply to market servers: First, when we motivated the versioning idea, the fragmentation of the market going along with the use of multiple market models was not mentioned. Different to other information goods, by differentiation markets loose some of their ability to supply liquidity. The existence of network effects can offset the positive effects created by tailored market models. Second, configuring market models always entail a thorough testing procedure. In complex environments such as a market server testing can become extremely expensive reducing the implementation savings. Whether or not comprehensive market servers will find their way into B2B markets, is a question of technical feasibility and reliability.

\subsection{Hypothesis 2: Dynamic Market Models help to meet customers' needs}

Dynamic Market Models (henceforth DMM) can be regarded as a special form of multiple (generic) market models. In fact, DMMs also provide multiple market models. The peculiarity lies in the accentuation of the participants' involvement in the design process (Budimir, Holtmann et al. 2002). That is, the participants transaction-wisely self-construct their most convenient trading vehicle. The definition comprehends three elements:

\section{(1) Self-Selection}

The fundamental idea behind dynamic market models is that free market forces can do a better job in choosing the appropriate market model than a system designer or a professional exchange (Amihud, Mendelson 1985). The provision of several market models creates a competitive environment among the alternatives. Since information about the participants' preferences is dispersed, by the competitive play of demand and supply a market of market models may eventually work out the superior ones. Lack of usage, unsuccessful market models will naturally pass away.

The last argument leads to the question what market models have proven their contestable nature in real life? The answer is not easy: in securities markets mainly three categories of models namely dealer markets, clearinghouse, and open auctions (Madhavan 1992) have been prevailing (e.g. NASDAQ employs a dealer market). Nonetheless, in B2B-markets other types of market models have been established such as procurement models with reverse auction formats (Milgrom 2000). The crucial question whether 
or not a market model is superior is apparently dependent on the properties of the traded good or service. Summarizing, there does not exist a "one-size fits it all mechanism" (Wurman 1999).

\section{(2) Construction}

Unlike the versioning idea of multiple markets, dynamic market models do not provide packages (market models) from which to choose from. Instead they embody a toolkit for creating market models. The participants can choose their preferred parameter values. For example the market participant selects a double auction with an anonymous bidding procedure. Principally, the entire design space, given by the dynamic market server, can be configured. Dynamic markets in their pure form mark an extreme point: it could simply mean that any order (bid or ask) builds its own market. Bid and ask offers are, however, complements. A transaction occurs only on corresponding matches. If every order were stranded on ones "market island", the total market would collapse. On the other hand there is a natural tendency for markets to converge, as increased liquidity arising from scale is clearly a benefit (Pagano 1989; Chowdhry, Nanda 1991). Nonetheless, this convergence property can be enhanced by limiting the design space in order to increase the probability that a sufficient number of trades fall into the same market. This can be achieved by employing building blocks. The system designer has to compose some common value parameters to a building block. For example an auction format (e.g. English auction) already embodies a building block, since bidding (open bids) and clearing (highest bid obtains the good and pays the price that he bids (McAfee and McMillan 1987 ) is pre-determined. In this case, the investor can select a specific auction and subsequently configure the trading frequency and the priority rules.

\section{(3) Transaction-wise nature}

The concept of dynamic market models endows the participants for any transaction with multiple trading mechanisms. The reason for this stems from the instability of the participants' preferences. The trading motive and accordingly the suitable trading mechanism can change from one situation to another. For instance, a broker-dealer may have different demands when trading on his own instead of his customer's account; additional changes in his demand might occur depending on the size of each special order. This problem exhibits that preferences are not stable over time. Hence, the principle of free markets demand for a transaction wise selection of market models.

Summarizing, DMMs tremendously increase the customer-orientation of market models. This occurs, however, on the expense of liquidity. Market fragmentation may offset the beneficial effects of tailored trading vehicles. 


\subsection{Hypothesis 3: Cascading Market Models alleviate market fragmentation}

As we have demonstrated, DMMs are a reasonable solution to enhance customer orientation by providing specialized designs to relevant groups of market participants. On the other hand DMMs build up a multiple market structure within one platform.

The question whether the existence of multiple markets and DMMs for the same good has primary positive or negative effects has been discussed for a long time and remains open (for an overview see Davis 1985, footnote 17; Harris 1995). Discussions about this topic include for example the following criticisms:

- DMMs tend to split up liquidity which ends up in higher (implicit) transaction costs,

- transparency decreases and information costs increase when products are traded on DMMs,

- market supervision becomes more evident as new problems like payment for order flow emerge.

But there are also positive effects mentioned in this literature. Competition for order flow between e-markets improves customer orientation:

- Fees are reduced,

- services are optimized,

- innovations to increase market efficiency are stimulated,

- and finally heterogeneous participants' needs can be regarded.

A DMM structure seems to be reasonable, if the benefit - the (heterogeneous) investors get out of the sum of specialized market structures - exceeds the disadvantages following the reduced efficiency. The key to higher efficiency of multiple markets is a question of market integration (Harris 1995, p. 284).

In securities trading integration of e-markets can be easily achieved when information flows unrestricted between e-market and at least some participants have access to both e-markets, e.g. arbitrageurs (Harris 1995, p. 285). These market participants accommodate temporary differences between prices in the e-markets by buying at one and selling at the other emarket. The extend to which especially arbitrageurs can level price differences depends upon the trading costs: fixed costs for the establishment of market entrance and cost depending on each single transaction like commissions, fees, but also information and risk costs. Arbitrageurs might emerge ,automatically" but can also be "part" of the e-market design.

As a first alternative market makers can be integrated into the design (Stoll 1985). These institutional market participants build up indirect market connections by acting in different markets. 
A second alternative is to establish direct connections, meaning that orders in one e-market can directly be executed against those from another. Each market participant acts on different e-markets. This second point leads to the idea of cascading market models.

Cascading dynamic market models (cDMM) extend the dynamic market model concept. The market participant may separately choose the design best fitting his needs for each transaction. In this case all single market models are integrated within one order book. When market models are cascading, market inefficiencies stemming from decreases of liquidity and transparency can be reduced. On the other hand cDMM increases efforts in market supervision.

The concept of cascading market models is not as straightforward. The example of the VTR prototype ${ }^{5}$ may help to grasp its notion (for a detailed illustration see Budimir, Holtmann 2001):

To meet the heterogeneous investors' needs that have been detected in a number of interviews and discussions with experts during the last year, three different market models have been designed. The basis for all market models is the following set of parameter values: open order book, open bid and ask orders according to price-time priority.

- The VTR order book comes with traditional market maker functionality. A market maker acts as a liquidity provider and has to provide a public quotation. Private investors can hit his bid (ask) quotation in the order book to sell (buy) at the given price. All trades are bilateral trades between a private seller (buyer) and the market maker.

- The hit-and-take-market (HNT) implementation is a hybrid price discovery mechanism derived out of a continuous auction and a simple bulletin board, giving all the market participants the chance to either place limit orders, or to "hit-and-take" existing orders (not to mix up with the mentioned quotations of the market maker) from the order book. All trades can be seen as bilateral trades between a private buyer and a seller.

- The chat market is a price discovery mechanism where two or more parties electronically negotiate with each other. It is the electronic depiction of the traditional OTC telephone market. The combination of the HNT and the chat functionality leads to the hit-and-chat

5 The Virtual Trading Room (VTR) is an electronic trading system for after-hours stock trading of private investors. Three different systems are commonly used in Germany, but as there are contractual agreements between brokers and system operators, normally the single investor has only access to one of them. Integration of these markets is not given on the order-by-order but on the market maker layer, as some market makers work as liquidity providers for more than one system. VTR has been developed as a research prototype and is now build for practical use by trading-fair AG, Giessen, Germany. 
market (HNC), that being a HNT market that is replenished with the features of a chat market. During the specification of a limit order, a trader can specify whether he wishes to transact only via the order book, or if he signals the willingness for further negotiations. If so, other traders can either "hit-and-take" an order from the book (thereby accepting the posted conditions) or initiate an interactive electronic negotiation about the price.

Due to the fact that an investor individually decides which price discovery mechanism he prefers, VTR represents the case of DMM. As all three mechanisms are integrated within one market, we obtain a cDMM.

Experiments have been performed to analyze the acceptance and consequences of this kind of market models. The main topic of interest was the case of asymmetrical informed participants using innovative market mechanisms (Budimir, Holtmann 2001). Experimental results show that there is substantial benefit to expect from the illustrated concepts. The investors utilize alternative and innovative trading mechanisms ${ }^{6}$ and even if these mechanisms are not utilized the pure existence of alternatives within one market can have positive externalities for the quality of the whole market. ${ }^{\text {? }}$

In future experiments further aspects of $\mathrm{CDMM}$ such as price efficiency and anonymity will be analyzed.

\section{CONCLUDING REMARKS AND FURTHER RESEARCH}

Although electronic markets have the undisputed ability to improve traders' value and the efficiency of coordination as a whole, many existing emarkets disappeared in recent years. One important reason for their decline appears to be the inappropriate e-market design.

Recall, that the complexity of e-market design issues is illustrated by five integral aspects, namely that of: (a) the size of the design space, (b) uncertainty about the impact of the single values on the market performance, (c) uncertainty about the impact of market models on the market

${ }^{6}$ In the first setting of the experiments which is illustrated in Budimir and Holtmann 2001 the acceptance of the HNC mechanism has been very small. The second setting, which is not yet published, demonstrates that this can be ascribed to the huge number of liquidity providers within the system. ${ }^{6}$ For example liquidity traders achieved their goals with a lower number of trades.

${ }^{7}$ For example liquidity traders achieved their goals with a lower number of trades. 
performance, (d) heterogeneous preferences among investor groups, and (e) inconsistent preferences over time.

a) The problem of the huge design space is still prevalent and probably will ever remain unsolved. Our suggested approach of cDMM explicitly supports the construction of new market models by traders. However, one way to reduce complexity is to establish components of market models, building blocks. The participants no longer choose the single parameter values but - less in number building blocks. The question of the right-sized granularity of building blocks is subject to future experimental analysis.

b) The presented approaches do not contribute to discover the pure effects of the values on the market quality (e.g. efficiency). The focus of our work is more on the composite effect of many parameter values working together in a market model. Nonetheless, the study of the pure effects is essential for designing useful market models. If the pure effect is completely ambiguous then it is even more difficult to identify reasonable building blocks.

In the field of securities trading market microstructure theory supplies designers with numerous helpful aspects. Whereas in other fields of ecommerce the market microstructure is not nearly as well understood as securities markets.

c) The identification of the effect a market model has on the market quality, is clearly one of our main goals. However, due to the myriads of possible market models only some market models can be evaluated. In the cDMM approach arises another problem: The impact of market models cannot separately observed, since the emarkets are connected. The interaction of the market models can create external effects. Just the possibility of multiple trading vehicles can change the market behavior and thus the overall market quality.

d) To address heterogeneous preferences multiple market models are deployed, as one single model always favors one group on expense of another.

e) Inconsistent preferences over time can be regarded by the utilization of dynamic market models (DMM), as these give the investor the possibility to self-select the best fitting alternative transaction by transaction.

The concept of cascading dynamic market models (cDMM) is introduced as a possible solution to reduce efficiency losses that might occur when multiple market models exist for the same product. With the VTR an experimental system for ongoing surveys was briefly introduced that serves as a proof of concept that IT systems can be build upon the concept of cDMM for a given use case. Open research questions remain, since the concepts so far lacks a concrete model which and how different price 
determination and market models could or should be integrated. In order to address the remaining issues further theoretical, empirical and experimental research is encouraged.

With this goal the project 'Electronic-Financial-Brokerage as knowledgeintensive services - a generic approach' was launched as a joint venture of researchers and practitioners. The partners of the project, boerse-stuttgart AG, Reuters AG and trading-fair AG together with the Chair of Information Management and Systems of the University of Karlsruhe, are developing theoretical concepts and transfer those into the practical environment.

The main focus of the project team is to develop a personalized, generic (in the sense of multi-product) market platform supporting cDMMs. This platform allows exploring the problem space $<\mathrm{P}, \mathrm{V}_{\mathrm{i}}, \mathrm{C}, \operatorname{Pr}>$ (see section 2) in the following manner:

Managing "multi-products" e.g. commodities and services, often require multi-dimensional negotiation facilities. Unlike highly standardized securities such as stocks, commodities and services are determined by more attributes than the price. For instance a car comprises a price, a color, a trunk size, and many more. All attributes might be not strict but negotiable. This means the negotiation object can be tailored to the needs of the participants along the negotiation process (log-rolling). In our example the intense negotiation between buyer and seller can render the following compromise: the buyer accepts a red instead of a blue car if he gets a discount of $10 \%$ on the price (Kersten 2000 , p. 3). The example already hints at the problem of transforming non-price attributes to an aggregate (utility or score) value. Accordingly multi-attribute market models must also contain a scoring mechanism. This means for the market model structure, that not only new values are added, but also additional parameters (such as a scoring facility).

One goal of the project is to identify reasonable parameters $\mathrm{P}$ with their corresponding values $V_{i}$ by the means of experiments. Furthermore a conceptual framework of multi-dimensional market models is intended, where the construction rules and constraints $\mathrm{C}$ are adequately defined. Another vivid question is the deployment of cascading market models in the case of multi-dimensional commodities and services. More attributes tremendously increase the complexity of connecting market models.

Last but not least the preferences Pr of the market participants have to be explicitly analyzed. Therefore empirical surveys are conducted in order to segment the investors' needs and to measure their time-inconsistency.

A more sophisticated e-market design may bolster the (re-)rise of emarkets. 


\section{REFERENCES}

Amihud Y., Mendelson H. "An Integrated Computerized Trading System." In Market Making and the Changing Structure of the Securities Industry. Y. Amihud, T. Ho, R. A. Schwartz, (eds.) Lexington Books 1985, 217-235, 1985.

Arrow K. J. Social Choice and Individual Values. New York, Wiley, 1963.

Brown D. C. "Intelligent Computer Aided Design". In Encyclopedia of Computer Science and Technology. A. K. J. G. Williams, Marcel Dekker, Inc. 28, 1993.

Budimir M., Holtmann, C. "The Design of Innovative Securities Markets: The Case of Asymmetric Information" In e-Finance: Innovative Problemlösungen für Informationssysteme in der Finanzwirtschaft. H. U. Buhl, N. Kreyer and W.Steck ed., IL: Springer: $2001 ; 175-196$.

Budimir M., Holtmann C., et al. "The Design of a Best Execution Market." Revue Bancaire et Financière/ Banken Financiewezen (Special SUERF Dossier): forthcoming (2002).

Bulow J., Roberts J. The simple economics of optimal auctions. Journal of Political Economy 97; 1989; 5: 1060-1090.

Capers C., Bartels, A., et al. B2B Exchanges: Future Hopes, Current Doubts. Booz Allen Hamilton and Giga Information Group 2001.

Chowdhry B., Nanda V. Multi-Market Trading and Market Liquidity. Review of Financial Studies 1991; 3: 483-511.

Davis J. L. The Intermarket Trading System and the Cincinnati Experiment. Market Making and the Changing Structure of the Securities Industry. In Y. Amihud, T. Ho, R. A. Schwartz, (eds.) Lexington Books: 269-283, 1985.

Forrester Research Anatomy of New Market Models. Forrester Research 1999.

Harris L. E. Consolidation, Fragmentation, Segmentation, and Regulation. Global Equity Markets - Technological, Competitive, and Regulators Challenges. R. A. Schwartz. Chicago, Irwin Professional Publishing: 1995; 269-301.

Idapta eMarkets to Face Market-Driven Challenges. http://www.idapta.com/insight/whitepapers/; 2000.

Kersten G. E. Are All E-Commerce Negotiations Auctions? At: International Conference on the Design of Cooperative Systems (COOP'2000), Sophia-Antipolis 2000.

Knight L. Triggering the B2B Electronic Commerce Explosion, Gartner Group 2000.

Madhavan A. Trading Mechanisms. In Journal of Finance 1992; 47: 607-641.

Malone T. W., Yates J., et al. Electronic Markets and Electronic Hierarchies. In: Communications of the ACM 30 1987; 6: 484-494.

McAfee P. McMillan, J. Auctions and Bidding. Journal of Economic Literature 1987; 25: 699738.

Milgrom P. R. An Economist's vision of the B-to-B-marketplace. An Executive White Paper, Palo Alto: perfect.com, October 2000.

Motta E. Zdrahal, Z. Parametric Design Problem Solving. At: 10th Banff Knowledge Acquisition for Knowledge-Based Systems Workshop. 1996.

O'Hara M. Market Microstructure Theory. Malden: MA, Blackwell Publishers Inc., 1997.

Pagano M. Trading Volume and Asset Liquidity. Quarterly Journal of Economics 1989; 104: 255-274.

Roth A. E. Game Theory as a Tool for Market Design. In Game Practice: Contributions from Applied Game Theory. F. Patrone, I. Garcia-Jurado, Tijs, S. IL: Kluwer: 2000 7-18.

Shapiro, C. Varian H. R. Information Rules. Boston, MA, Harvard Business School Press, 1999. 
Stoll H. R. "Alternative views of market making" In Market Making and the Changing Structure of the Securities Industry. Y. Amihud, T. Ho, R. A. Schwartz, (eds.) Lexington Books 1985: 67-92.

Varian H. R. Versioning Information Goods. Internet Publishing and Beyond. B. Kahin and H. R. Varian, The MIT Press 2000: 190-202.

Wrigley C. Design Criteria for Electronic Market Servers. Electronic Markets 1997 (4): 1216.

Wurman P. Market Structure and Multidimensional Auction Design for Computational Economies. Dissertation. School of Information, University of Michigan 1999.

Wurman P., Wellman M. P., et al. The Michigan Internet AuctionBot: A configurable auction server for human and software agents. Second International Conference on Autonomous Agents, Minneapolis 1998; 301-308. 